\title{
"Where will I belong more?": The role of belonging comparisons between STEM fields in high school girls' STEM interest
}

\author{
Jenny Veldman ${ }^{1,2}$ (D) Colette Van Laar ${ }^{1}$ (D) Dustin B. Thoman ${ }^{3}$ D . \\ Carolien Van Soom ${ }^{4,5}$ (D)
}

Received: 26 July 2021 / Accepted: 17 August 2021 / Published online: 30 August 2021

(c) The Author(s), under exclusive licence to Springer Nature B.V. 2021

\begin{abstract}
In trying to understand women's underrepresentation in STEM (Science, Technology, Engineering, Mathematics), most existing research focuses on one STEM-field or collapses across all STEM-fields. However, these fields differ vastly in female representation: women tend to be most strongly underrepresented in technological and computer science university majors and to a lesser extent in mathematics and chemistry, while they are less underrepresented in biological sciences. To understand this variability, we examine how girls in the process of making higher education choices compare different STEM-fields to each other. We draw upon dimensional comparison theory, which argues that educational motivation involves intra-individual comparisons of achievement across school subjects. However, previous research has shown that a focus on achievement in STEM is not enough, anticipated belonging in a STEM-field plays a pivotal role in interest in pursuing that field. Consistent with this, we examined participants' comparisons of anticipated belonging across STEM-fields. A sample of 343 high school girls in STEM-focused university tracks completed a survey on their anticipated belonging and interest in pursuing different STEM majors. Latent Profile Analysis resulted in 3 profiles, showing different belonging comparison patterns across STEM-fields. Examining these comparisons-both within and across profiles-showed how girls felt pushed away from certain STEM-fields and pulled toward others. The findings suggest that for interest in pursuing specific STEM-fields it is not just about the level of anticipated belonging within that STEM-field, but just as much about the level of anticipated belonging in comparison to another STEM-field.
\end{abstract}

Keywords Belonging · Women in STEM · Girls in STEM • Career interests · Dimensional comparisons · Gender

Jenny Veldman

jenny.veldman@kuleuven.be

Extended author information available on the last page of the article 


\section{Introduction}

Women's representation in Science, Technology, Engineering, and Mathematics (STEM) in Western countries has increased over the years. For example, in the US women now earn $37 \%$ of undergraduate STEM degrees (National Science Foundation, 2014), and in Belgium currently $41 \%$ of the incoming students at university STEM majors are women (STEM monitor, 2020). However, STEM fields differ vastly in terms of women's representation. Of the bachelor degrees awarded to women in the United States, the strongest underrepresentation is found in engineering, computer science, and physics $(<20 \%)$, followed by mathematics and chemistry with a slightly higher percentage of women $( \pm 40 \%)$, and then by biological sciences where women are no longer underrepresented at the undergraduate level $( \pm 55 \%$; Cheryan et al., 2017; National Science Foundation, 2014). The context of the present study is Belgium, where the distribution is similar even though the percentages of women in bachelors are slightly lower overall (KU Leuven, 2014): the highest percentage of women is in biochemistry, biology, and bio-engineering majors $( \pm 50 \%$; in the present study these fields are combined in a category 'Biological sciences'), followed by a lower percentage of women in mathematics, chemistry, and geology/geography majors $( \pm 35 \%$; in the present study these fields are combined in a category 'Mathematics and natural sciences'), followed by the lowest percentage of women choosing bachelor degrees in computer science, physics, and engineering $(<20 \%$; in the present study these fields are combined in a category 'Technological, physical, and computer sciences').

Although there are these differences in gender-representation between STEM fields, previous work often collapses these fields and looks at STEM overall (e.g., Belanger et al., 2020), or looks at one STEM field specifically (e.g., Cheryan et al., 2009; Good et al., 2012; see also Cheryan et al., 2017). In the present paper, we argue that to understand this variability in gender-representation it is key to examine how high school girls in the process of making higher education choices make comparisons between STEM fields in terms of anticipated belonging in the field, and how these comparisons relate to their interest in pursuing fields. Previous research has shown that anticipating belonging in a STEM field is key for interest in pursuing that STEM field (Master et al., 2016). By not only looking within fields, but also across fields, we gain more understanding as to how high school girls compare different STEM fields to each other, and how this not only pushes them away from certain STEM fields, but also pulls them towards others. In doing so, this research gains more understanding of why women are more underrepresented in some STEM fields than others.

\subsection{The influence of comparative processes on educational motivation and aspirations}

Comparative processes have been examined in the educational sciences literature in terms of ability self-concept and achievement motivation (Marsh et al., 
2019). One key theory in this domain is dimensional comparison theory (Möller \& Marsh, 2013), an extension of the internal/external frame of reference model (or I/E model; Marsh, 1986). Dimensional comparisons are individuals' comparison of their abilities in one set of activities (e.g., their math performance) with another set of activities (e.g., their verbal performance). These dimensional comparisons are argued to have an effect on people's ability self-concepts and aspirations. For example, a dimensional comparison that results in a student concluding that they are good at math, but not so good in reading, leads them to have a lower self-perception of their verbal ability compared to a student with identical verbal ability but lower math ability (and vice versa; Möller \& Marsh, 2013). Thus, this theory argues that students evaluate their ability in a domain or subject not in isolation but in relation to their ability in other domains or subjects ("How good am I in math compared to language?"), which affects their self-concept, motivational beliefs, and aspirations.

Previous research has shown the influence of these dimensional comparisons in different ways. First, the role of dimensional comparisons has been evidenced by research showing that students' self-concept and aspirations in a school subject are influenced by achievement in other subjects. For example, higher achievement in languages predicted lower motivational beliefs in mathematics (Guo et al., 2015; Jansen et al., 2015; for a meta-analysis see Möller et al., 2009). Experimental studies have confirmed the causal process, by showing that providing students with negative feedback about their performance on mathematical tasks increases their verbal ability self-concept (Möller \& Köller, 2001). Secondly, other studies have looked at relative differences between domains or subjects, showing that 15 -year-old girls who are good at math are much more likely than 15-year-old boys to be even better in reading, and that this comparative advantage in reading achievement partly explains the gender gap in intentions to pursue math-studies and careers (Breda \& Napp, 2019) and in STEM graduation (Stoet \& Geary, 2018). Thirdly, some studies have taken a more person-focused analytic approach, showing that students with both high math and verbal skills (who are more likely to be girls than boys) are less likely to pursue a STEM career compared to students with high math but low verbal skills (Wang et al., 2013). Combined, this previous research has shown in different ways that ability self-concept and aspirations are affected by a comparative process of achievement across different domains or school subjects (specifically, languages and mathematics). Increasingly, these intra-individual comparisons of achievement are seen as key to understand educational decisions and why individuals choose one career or major over another (Breda \& Napp, 2019; Wang \& Degol, 2013).

However, individuals might use other information available in a domain besides their achievement when they make dimensional comparisons (Möller et al., 2015, 2016). First research has indeed found support for this by showing that higher levels of perceived teacher support in one school subject was related to lower motivation in another subject (Dietrich et al., 2015). Following these findings, it was argued that any psychologically relevant construct in a domain can be used in dimensional comparisons (Möller et al., 2015, 2016; see also Wigfield et al., 2020). Furthermore, dimensional comparison theory has also been expanded to other domains besides the verbal subject and math, such as physics and chemistry. This expanded version 
of dimensional comparison theory is also called the generalized I/E model (Möller et al., 2015, 2016).

Following these developments, we argue that this comparative process might also be happening with different STEM fields, and can help understand variability in interest between STEM fields. Importantly, previous research has shown that a focus on achievement, expectancies for success, and ability self-concept is not enough to understand women's underrepresentation in STEM (Ceci et al., 2009; Law, 2018; Master et al., 2016; Wang et al., 2013). Therefore, we focus on dimensional comparisons regarding a construct that has shown to be particularly psychologically relevant to understand women's underrepresentation in STEM, namely belonging.

\subsection{Belonging plays a pivotal role in understanding women's underrepresentation in STEM}

Belonging is the most key human motive (Fiske, 2018; Leary \& Cox, 2008) - people have a fundamental need to fit in socially and to feel included, accepted, and at home (Baumeister \& Leary, 1995; Gabriel, 2021; Major \& Schmader, 2017; Ryan \& Deci, 2000; Vignoles, 2011). This belonging can be threatened in fields in which one's ingroup is a minority, in which there are negative stereotypes about one's ingroup, and in which characteristics are valued that are more strongly associated with the outgroup (Van Laar et al., 2019).

Previous research has established that belonging can be threatened for women in STEM, and that this plays a pivotal role in women's underrepresentation in STEM. For example, when undergraduate STEM students were exposed to a video of a STEM conference in which women were a strong numerical minority (vs. a more gender-balanced conference), women (and not men) experienced a lower sense of belonging and less desire to participate in the conference (Murphy et al., 2007). Furthermore, STEM fields emphasize characteristics such as brilliance, being selffocused and agentic, and analytic strength (Bian et al., 2017; Cejka \& Eagly, 1999; Leslie et al., 2015; Storage et al., 2020). These characteristics are stereotypically ascribed more to men than to women (Ellemers, 2018). This emphasis on masculine characteristics in STEM can make women more uncertain about their belonging in STEM and can lower their STEM interest. For example, Gaucher and colleagues (2011) showed that job advertisements with more stereotypically masculine wording made these jobs less appealing for women, and this was mediated by lower perceptions of belonging and not by perceived skills. The physical classroom environment can also communicate these stereotypes and affect women's sense of belonging and interest. Undergraduate women (Cheryan et al., 2009) or high school girls (Master et al., 2016) brought to a computer science classroom decorated with primarily stereotypically masculine objects (e.g., a Star Trek poster) reported a lower sense of belonging and interest in computer science than those brought to a classroom with objects not considered stereotypically male (e.g., nature posters). These classrooms had no differential effects on men (Cheryan et al., 2009) or high school boys (Master et al., 2016). More generally, girls' lower sense of belonging in computer science helps explain the gender gap in computer science interest, beyond negative 
stereotype concerns, success expectations, and utility value (Master et al., 2016). Similar results have been found among women in mathematics (Good et al., 2012). Finally, obtaining a sense of belonging in the field increases STEM motivation for undergraduate women (Thoman et al., 2014) and for female STEM graduate students (Smith et al., 2013). Importantly, this is not specific to women in STEM: having a sense of belonging in a field is more generally a strong predictor of interest in pursuing that field (Belanger et al., 2020; see also Cheryan et al., 2017). Thus, experiences and expectations of low belonging in STEM play a pivotal role in women's underrepresentation in STEM.

\subsection{The present research: belonging comparisons across STEM fields to understand variability in STEM interest}

As belonging is key to understand interest in pursuing STEM fields and women's underrepresentation in these fields, the present research looked at belonging comparisons between STEM fields. We argue that the anticipation of belonging varies across STEM fields. In STEM fields where women are more underrepresented, the field is more strongly associated with men and masculine characteristics, and negative stereotypes about women's abilities are more pervasive (Casad et al., 2019; Cheryan et al., 2017). Because negative stereotypes and emphasis on masculine characteristics threaten women's belonging in STEM, differences between STEM fields in representation likely lead to differential anticipation of belonging across STEM fields. In the present study, this would imply that high school girls anticipate the lowest belonging in Technological, physical, and computer sciences $(<20 \%$ women), followed by higher belonging in Mathematics and the natural sciences $( \pm 35 \%$ women), followed by higher belonging in Biological sciences $( \pm 50 \%)$. Importantly, although this might be the case on average, this does not mean that everyone has the same belonging comparisons across STEM fields. For example, exposure in their education to certain STEM fields, exposure to role models, or having had positive experiences in their education regarding specific STEM fields could increase girls' anticipated belonging in that STEM field (and, vice versa, negative experiences could reduce belonging; Cheryan et al., 2017). This could result in different comparisons across STEM fields, such as anticipating an equal level of anticipated belonging in Biological sciences as in Mathematics and natural sciences, rather than lower anticipated belonging in the latter field.

The present study examines these anticipated belonging patterns across STEM fields among high school girls. We expect that there are different groups that make different anticipated belonging comparisons across STEM fields, and take a personfocused approach that enables the identification of these groups. We examine how the different belonging comparisons are related to girls' interest in pursuing different STEM fields, and expect that this provides insight into how girls can feel pushed away from certain STEM fields and pulled towards other STEM fields. As such, we expect that examining these belonging comparisons across STEM fields can help us understand variability in interest between STEM fields. 
We examined this among high school girls, all in STEM-focused academic tracks, in a crucial stage of decision-making regarding their higher education. Specifically, these girls were in their fifth year of their six-year secondary education in Belgium-meaning that they were sampled one year before they have to make important, high-impact choices regarding higher education. This is a crucial decision-making stage in this educational context, since the higher education choice they make is rather fixed. Unlike in the US, where the freshman year can consist of a broad range of courses from various majors before making a final choice, the major in Belgium is chosen prior to college entry, the courses taken fit for a very large part only this major, and changing majors after making this choice is less likely. Furthermore, research has shown that underrepresentation of women in STEM is more attributable to a failure to recruit girls into these fields than a failure to convince girls who enter these fields to stay (Ceci et al., 2014; Cheryan et al., 2017). Therefore, gaining insight into why high school girls are more likely to be interested in choosing some STEM fields over others is a crucial step in trying to close gender gaps in STEM.

Participating girls completed a survey on their anticipated belonging and interest in pursuing different STEM majors. Latent Profile Analysis was conducted to examine profiles of anticipated belonging patterns across these three STEM fields. This analysis provides insight into common patterns of belonging comparisons that girls make across STEM fields, which was in turn compared to their interest in pursuing these different STEM fields.

\section{Methods}

\subsection{Participants and procedure}

The sample consisted of 343 girls with a mean age of $16.38(S D=0.57)$. Most participants (82.6\%) indicated being Belgian and 24.3\% (also) selected other groups, such as Dutch, French, Moroccan, or Algerian. Seven girls did not complete the belonging concerns measures, so data analyses were completed with $N=336$. There were no participant exclusions. Secondary education in Belgium is organized such that students are in different tracks based on academic level and on content. All participants were in an academic track preparing them for university, and in tracks with a strong focus on mathematics and the natural sciences (i.e., compared with other tracks they have in these tracks relatively high exposure to mathematics, physics, chemistry, and biology).

Data was collected in Spring during three consecutive years between 2018 and 2020. The majority of the sample was recruited when they registered with their high school class for an information event at the university's Faculty of Science. This event, called 'Ladies@Science', introduces girls who are one year before finishing high school to the different majors in the Faculty of Science and its possibilities (through workshops and testimonials of women working in the fields the majors represent). The organizers of the event are in touch with the high school teachers, who invite and encourage all fifth-year girls in academic tracks focused on mathematics 
and natural sciences to participate in this event. When they registered for the event by completing an online form the girls were also informed that they would be invited to participate in a study on their interests and choices regarding higher education (provided their parents did not object). They were told that the researchers were interested in gaining more insight into the choices they might make and what their considerations are in the process. In the online form, they gave their name and email address, and an email address of one of their parents. Parents received an email with an explanation of the study and were given an opt-out option if they wished their daughter not to participate. Girls could complete the online survey until the launch of the Ladies@ Science event. As part of this research project, girls were also invited to complete a survey after the event to assess their experiences during the event, and whether participation changed their perception of and interest in STEM. The present study focuses on the survey assessed before the event. In 2020 the event had to be cancelled due to the COVID-19 pandemic. This cancellation occurred after the event registration and registered girls were still invited for this study. Of the final sample, 35 girls were recruited not while registering for the Ladies@ Science event, but were directly invited by their teachers to participate in this study. If they were interested in participating, they entered in an online form their name and email address, and an email address of one of their parents. All other aspects were the same for this group.

The first page of the online survey consisted of an informed consent. The procedure of this study was approved by the University of Leuven's Social and Societal Ethics Committee (approval number G-2018 03 1170).

\subsection{Measures}

Measures were scored such that higher scores indicated stronger scores on the concept. As noted, the data reported in this study was part of a larger project. Below we describe the measures relevant to the present paper. The supplemental material provides an overview of additional measures not included in this manuscript. Table 1 shows the correlations between measures.

\subsubsection{Anticipated belonging concerns}

As an introduction to the anticipated belonging concerns measure, participants were told that "When we do new things we sometimes feel out of place and struggle in the beginning. At other times we feel comfortable and at ease". Next, they were asked to imagine that they follow an education in several fields: Biological sciences (bio-engineering, biochemistry, biology), Mathematics and natural sciences (mathematics, chemistry, geology, geography), and Technological, physical, and computer sciences (physics, computer science, civil engineering, industrial engineering). For each of these three STEM fields, participants were asked with two items to indicate on a scale from 1 (not at all concerned) to 7 (very concerned) the extent to which they would be concerned about experiencing "feeling like you do not belong" and "feeling excluded" in such a field (based on Good et al., 2012; Master et al., 2016; Smith et al., 2013). These items were correlated as follows for the three 


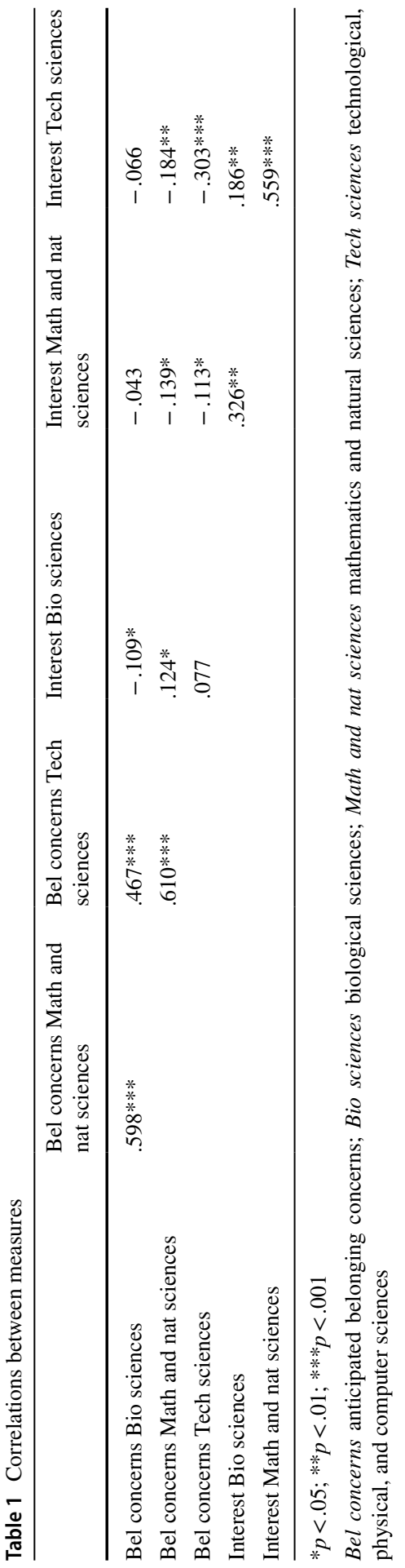


STEM fields: Biological sciences: $r=0.67, p<0.001$; Mathematics and natural sciences: $r=0.63, p<0.001$; Technological, physical, and computer sciences: $r=0.69$, $p<0.001$.

\subsubsection{Higher education interests}

To assess interest in pursuing the different higher education fields, girls were asked to indicate on a scale from 1 (not at all interested) to 7 (very interested) to what extent they were interested to potentially follow an education in each of the study fields in a list of 20 fields in total. To be able to compare the belonging profiles in the different fields with the higher education interests in the same fields, scales for these education fields were created that match the fields as assessed in belonging concerns: Biological sciences (3 items: bio-engineering, biochemistry, biology; $\alpha=0.71$ ); Mathematics and natural sciences (3 items: mathematics, chemistry, geology/geography; $\alpha=0.51$ ); and Technological, physical, and computer sciences (4 items: physics, computer science, civil engineering, industrial engineering; $\alpha=0.72$ ).

\section{Results}

\subsection{Overview}

The goal of this study was to examine anticipated belonging patterns across STEM fields. We expected to find different groups of high school girls who make different belonging comparisons across STEM fields, and that this could help understand variability in interest across STEM fields. We started to analyze this by conducting a Latent Profile Analysis. This person-focused analysis enables the identification of groups of individuals who are similar to each other and different from others in other profile-groups in terms of their anticipated belonging patterns across the STEM fields (Hickendorff et al., 2018). This implies that individuals are classified in distinct profiles based on patterns that emerge across several fields. Thus, instead of comparing the mean anticipated belonging concerns of the STEM fields to each other to see whether girls experience more concerns in some fields compared to others overall-as one would do in a variable-focused approach-this person-focused approach allows for this belonging pattern not to be the same for all participants, and gives space for heterogeneity to arise in belonging concerns between STEM fields.

\subsection{Latent profile analysis: variability in anticipated belonging concerns between STEM fields}

We performed a Latent Profile Analysis in Mplus 5 (Muthén \& Muthén, 1998). Parameters were estimated using maximum likelihood estimation with robust standard errors, the Mplus default for mixture models such as LPA. We used the settings as recommended by Geiser (2013). Five-hundred random starts were used and of 
Table 2 Summary of model fit indices for LPA models specified with 2 to 5 profiles

\begin{tabular}{lllllll}
\hline $\begin{array}{l}\text { Number of } \\
\text { profiles }\end{array}$ & $\begin{array}{l}\text { Number of free } \\
\text { parameters }\end{array}$ & AIC & BIC & aBIC & VLRT (aLRT) & Entropy \\
\hline 2 & 10 & 3614.667 & 3652.838 & 3621.117 & $p=.0136(.0157)$ & 0.682 \\
3 & 14 & 3522.655 & 3576.094 & 3531.684 & $p=.0351(.0386)$ & 0.771 \\
4 & 18 & 3511.684 & 3580.392 & 3523.294 & $p=.3063(.3155)$ & 0.744 \\
5 & 22 & 3493.207 & 3577.183 & 3507.397 & $p=.6992(.7051)$ & 0.774 \\
\hline
\end{tabular}

Table 3 Classification probabilities for profile-group membership

\begin{tabular}{llll}
\hline Profile-group & 1 & 2 & 3 \\
\hline 1 & .898 & .043 & .059 \\
2 & .110 & .890 & .000 \\
3 & .099 & .000 & .901 \\
\hline
\end{tabular}

the 500 sets of start values in the first step of the optimization, 50 starting values are picked that show the largest log likelihood values in this first step for the second step of the optimization process, until a convergence criterion is reached. The number of iterations was set to 100 . These models converged to proper solutions, which replicated many times.

To determine the number of latent profile-groups, we examined groups with increasing numbers of profiles and compared model fit indices. We most strongly weighted the decision of group retention based on likelihood ratio tests (VLRT and aLRT), but also examined other fit indices (AIC, BIC, aBIC). Additionally, we examined indicators of cohesion (entropy), classification probabilities (i.e., how well the profiles can be distinguished from each other), and group size (as recommended by Marsh et al., 2009; see also Smith et al., 2014). Significance of the likelihood ratio tests indicates that the model being tested provides a better fit with the data than model with one fewer groups. Table 2 shows the model fit indices of models with 2 to 5 groups. The improvement of a 3-profile solution was significant according to the likelihood test (VLRT and aLRT). The entropy of the 3-profile solution was also higher compared to the 2-profile solution (indicating that it is better able to distinguish students with distinct profiles). The 4-profile solution was not a significant improvement in model fit according to the likelihood tests, and the size of one group also became relatively small $(n=30$; in the 5-profile solution there was one group of $n=36$ ). Finally, although the 3-profile solution did not have the highest model fit according to AIC and aBIC, the improvement in model fit after the 3-profile solution (to a 4- or 5-profile solution) was much smaller compared to the improvement of the 3- versus the 2-profile solution (for a similar consideration see Smith et al., 2014). The classification data provided in Table 3 also demonstrates that these 3 profilegroups are clearly distinguishable with strong classification probabilities (i.e., probabilities above 0.80; Rost, 2006; see Geiser, 2013). Thus, these analyses converge to indicate that in the present sample of high school girls, belonging concerns profiles across STEM fields are optimally represented by 3 latent profile-groups. 
Table 4 Estimated means and standard errors for belonging concerns in the three STEM fields by profile-group

\begin{tabular}{|c|c|c|c|c|c|c|c|}
\hline \multirow[t]{2}{*}{ Profile-group } & \multirow[t]{2}{*}{ Group size (n) } & \multicolumn{2}{|c|}{$\begin{array}{l}\text { Belonging } \\
\text { concerns } \\
\text { Biological } \\
\text { sciences }\end{array}$} & \multicolumn{2}{|c|}{$\begin{array}{l}\text { Belonging } \\
\text { concerns } \\
\text { Mathemat- } \\
\text { ics and } \\
\text { natural } \\
\text { sciences }\end{array}$} & \multicolumn{2}{|c|}{$\begin{array}{l}\text { Belonging } \\
\text { concerns } \\
\text { Techno- } \\
\text { logical, } \\
\text { physi- } \\
\text { cal, and } \\
\text { computer } \\
\text { sciences }\end{array}$} \\
\hline & & $M$ & S.E & $M$ & S.E & $M$ & S.E \\
\hline 1 & 179 & 3.34 & .24 & 3.73 & .28 & 4.22 & .16 \\
\hline 2 & 75 & 5.07 & .20 & 5.77 & .32 & 5.69 & .16 \\
\hline 3 & 82 & 2.08 & .21 & 1.82 & .13 & 2.33 & .54 \\
\hline
\end{tabular}

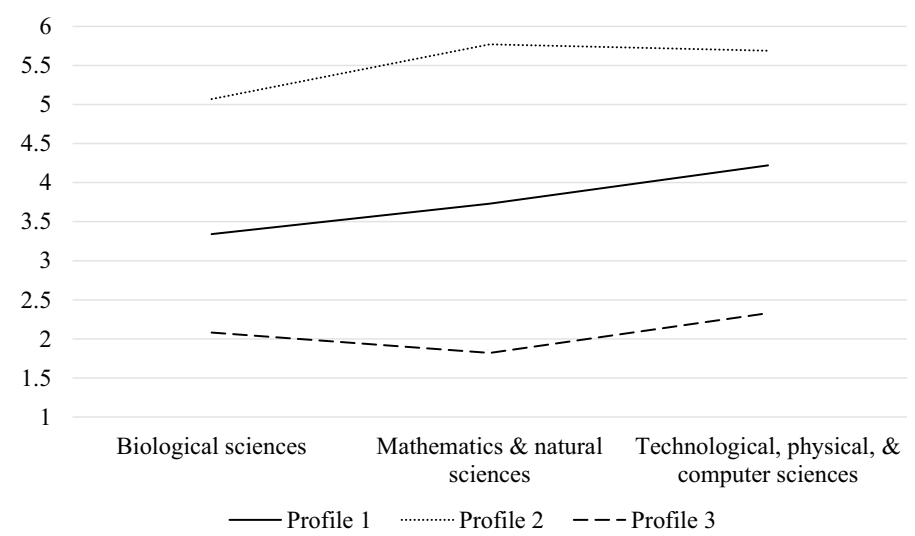

Fig. 1 Means for belonging concerns in the three STEM fields by profile-group

Next, we examined the group sizes and the estimated means and variances for belonging concerns in the three STEM fields for each profile-group (see Table 4). Figure 1 presents the profile plot of these means for the 3-profile solution. Examination of Fig. 1 suggests that the profile-groups differ quantitatively in terms of profile level. More important for the present research goal, however, are the qualitative differences in profile shape. That is, an inspection of the profile shapes shows, in line with expectations, that within the profiles there is heterogeneity in belonging concerns across STEM fields - the profiles differ in the anticipated belonging comparisons across STEM fields.

To inspect these comparative differences between STEM fields within each profile-group, we conducted paired-samples t-tests for each profile, testing whether the mean differences in belonging concerns across STEM fields was significant. To be able to conduct these analyses, we extracted profile-group membership for each participant from the above models and this profile membership was then used for a multi-group analysis. The results of these comparative analyses are discussed below for each profile-group separately. 


\subsubsection{Profile 1}

This profile (53\% of the sample) represents the largest group of high school girls. Compared to girls in the other profiles, they show average levels of belonging concerns across fields. Within this profile-group, all STEM fields differ significantly from each other in terms of belonging concerns. They report lower belonging concerns in Biological sciences compared to Mathematics and natural sciences $(t(178)=-3.65, p<0.001, d=0.27)$ and compared to Technological, physical, and computer sciences $(t(178)=-6.37, p<0.001, d=0.47)$. They also reported relatively lower belonging concerns in the Mathematics and natural sciences compared to the Technological, physical, and computer sciences, $t(178)=-4.24, p<0.001$, $d=0.32$. Thus, this group of high school girls had higher belonging concerns in a field the more that women are underrepresented in that field.

\subsubsection{Profile 2}

This profile ( $22 \%$ of the sample) represents girls who, compared to those in other profiles, have relatively high anticipated belonging concerns across fields. However, there are differences between STEM fields within the profile. Paired-samples t-tests showed that they report lower belonging concerns in Biological sciences compared to Mathematics and natural sciences $(t(73)=-3.66, p<0.001, d=0.42)$, and also compared to Technological, physical, and computer sciences $(t(73)=-3.43$, $p=0.001, d=0.40)$. Unlike Profile 1 , no significant difference in belonging concerns was found between Mathematics and natural sciences and Technological, physical, and computer sciences, $t(73)=0.91, p=0.367, d=0.10$. Thus, this group of high school girls had overall high belonging concerns, but less so in Biological sciences (the field with the highest female representation) compared to the other two STEM fields.

\subsubsection{Profile 3}

The final profile ( $25 \%$ of the sample) represents girls who, compared to those in the other profiles, have relatively low belonging concerns across fields. Again, there are differences between STEM fields within the profile, but the belonging comparisons are different than in the other two profiles. The girls within this profile showed marginally significantly lower belonging concerns in the Biological sciences compared to the Technological, physical, and computer sciences $(t(81)=-1.76, p=0.082$, $d=0.19$ ). In this profile, girls also reported (in contrast to the other two profiles) higher concerns in Biological sciences compared to Mathematics and natural sciences, $t(81)=2.24, p=0.028, d=0.24$. Finally, they reported (similarly to the other two profiles) lower belonging concerns in the Mathematics and natural sciences compared to the Technological, physical, and computer sciences, $t(81)=-3.92$, $p<0.001, d=0.43$. Thus, girls in this profile-group showed low anticipated belonging concerns overall, and relatively the lowest concerns in Mathematics and natural sciences and relatively the highest concerns in Technological, physical, and computer sciences (the field with the strongest female underrepresentation). 
Table 5 Means and standard errors for interest in pursuing the three STEM fields by profile-group

\begin{tabular}{|c|c|c|c|c|c|c|c|}
\hline \multirow[t]{2}{*}{ Profile-group } & \multirow[t]{2}{*}{ Group size $(n)$} & \multicolumn{2}{|c|}{$\begin{array}{l}\text { Biological } \\
\text { sciences }\end{array}$} & \multicolumn{2}{|c|}{$\begin{array}{l}\text { Mathemat- } \\
\text { ics and } \\
\text { natural } \\
\text { sciences }\end{array}$} & \multicolumn{2}{|c|}{$\begin{array}{l}\text { Techno- } \\
\text { logical, } \\
\text { physi- } \\
\text { cal, and } \\
\text { computer } \\
\text { sciences }\end{array}$} \\
\hline & & $M$ & S.E & $M$ & S.E & $M$ & S.E \\
\hline 1 & 179 & 4.06 & .09 & 3.49 & .08 & 2.90 & .08 \\
\hline 2 & 75 & 4.27 & .14 & 3.47 & .15 & 2.69 & .14 \\
\hline 3 & 82 & 4.06 & .15 & 3.83 & .13 & 3.46 & .15 \\
\hline
\end{tabular}

\subsection{Comparing variability in belonging concerns to variability in STEM interest}

The person-focused Latent Profile Analysis reported above revealed, as expected, different profiles that made different belonging comparisons across STEM fields. The next step is to examine whether this comparative focus on belonging concerns between STEM fields can also help understand variability in interest across STEM fields. To assess this, we again conducted paired-sample t-tests for each belonging profile-group, but this time with their interest in pursuing STEM fields. We tested whether the mean difference in interests (see Table 5) was significant across STEM fields, and examined how the interest comparisons across STEM fields related to participants' anticipated belonging comparisons.

\subsubsection{Profile 1}

High school girls in this profile showed higher anticipated belonging concerns the more women are underrepresented in the STEM field. Their interest in pursuing these fields mapped onto this belonging pattern. They reported being more interested in Biological sciences compared to Mathematics and natural sciences $(t(178)=5.73$, $p<0.001, d=0.43)$ and compared to Technological, physical, and computer sciences $(t(178)=10.69, p<0.001, d=0.80)$. Additionally, they indicated being more interested in pursuing Mathematics and natural sciences compared to Technological, physical, and computer sciences, $t(178)=6.67, p<0.001, d=0.51$. Thus, for this profile-group (which contained the majority of participants) the anticipated belonging comparisons across STEM fields matched the comparisons of interest.

\subsubsection{Profile 2}

The group of high school girls in this profile showed overall high anticipated belonging concerns, but relatively lower concerns in Biological sciences than in the Mathematics and natural sciences and than in the Technological, physical, and computer sciences (which did not differ significantly from each other). In terms of interest in pursuing these STEM fields, this group had more interest in pursuing Biological 
sciences than Mathematics and natural sciences $(t(73)=5.07, p<0.001, d=0.60)$ and than Technological, physical, and computer sciences $(t(73)=9.54, p<0.001$, $d=1.11$ ). However, even though they had equal level belonging concerns in the Mathematics and natural sciences and the Technological, physical, and computer sciences, they still showed more interest in pursuing the Mathematics and natural sciences $(t(73)=7.47, p<0.001, d=0.86)$.

\subsubsection{Profile 3}

The girls in this profile showed overall low anticipated belonging concerns, with relatively higher belonging concerns in the Technological, physical, and computer sciences and lower in the Mathematics and natural sciences. Unlike the other two profiles, this profile did not have significantly more interest in Biological sciences compared to both other STEM fields. Their interest in Biological sciences and Mathematics and natural sciences did not differ significantly $(t(81)=1.28, p=0.205$, $d=0.15$ ), even though they did have more concerns in the former field. Girls in this profile did report more interest in pursuing Biological sciences compared to Technological, physical, and computer sciences, $t(81)=3.07, p=0.003, d=0.34$ (even though their concerns in Biological sciences were only marginally significantly lower). Finally, they also reported more interest in pursuing Mathematics and natural sciences compared to Technological, physical, and computer sciences $(t(81)=2.93$, $p=0.004, d=0.32$ ), in line with the difference in anticipated belonging concerns.

\subsubsection{Interest differences between profiles}

Finally, to get insight into the full picture, we also compared interest in the three different STEM fields between profiles. A Multivariate Analysis of Variance showed that between the three profile-groups there were significant differences in interest in the three STEM fields, $F(6,662)=3.78, p=0.001, \eta_{\mathrm{p}}{ }^{2}=0.03$. Next, we examined the ANOVA for differences between the profile-groups for each STEM field separately.

First, the analysis of variance on interest in pursuing Technological, physical, and computer sciences showed a significant difference between profiles, $F(2$, $334)=9.62, p<0.001, \mathrm{\eta}_{\mathrm{p}}{ }^{2}=0.06$. Post-hoc tests (LSD) indicated that Profile 1 and 2 did not differ significantly from each other $(d=0.18, p=0.191)$. Profile 3 did report more interest in pursuing Technological, physical, and computer sciences than Profile $2(d=0.64, p<0.001)$ and Profile $1(d=0.48, p<0.001)$. Thus, the profile with the lowest belonging concerns in Technological, physical, and computer sciences showed the highest interest in pursuing this field. Additionally, even though Profile 2 had higher belonging concerns in this field than Profile 1, the interest of these two profile-groups in pursuing the field did not differ significantly.

An analysis of variance on interest in pursuing Mathematics and natural sciences showed a marginally significant difference between profiles, $F(2,334)=2.74$, $p=0.066, \eta_{\mathrm{p}}{ }^{2}=0.02$. Post-hoc tests (LSD) showed that Profile 3 (the group of girls with the lowest belonging concerns across STEM fields overall compared to the other two profiles) reported more interest in pursuing Mathematics and natural 
sciences compared to Profile $1(d=0.30, p=0.028)$ and marginally compared to Profile $2(d=0.29, p=0.058)$. Profile 1 and 2 did not differ significantly from each other $(d=0.02, p=0.936)$. Although these effects were less strong, again the profile with the lowest belonging concerns in the field showed the highest interest in pursuing the field; and again there was no difference in interest between Profile 1 and 2, even though Profile 1 anticipated lower belonging concerns in Mathematics and natural sciences compared to Profile 2.

Finally, even though the profiles differed in their level of belonging concerns in the Biological sciences, an analysis of variance did not show a significant difference between profiles in interest in pursuing Biological sciences, $F(2,334)=1.25$, $p=0.446, \mathrm{\eta}_{\mathrm{p}}{ }^{2}=0.01$. This might be the case because even though girls in Profile 2 report the highest belonging concerns in Biological sciences compared to girls in Profile 1 or Profile 3, within their profile they still have lower belonging concerns in Biological sciences compared to the other two STEM fields. This could explain why girls in Profile 2 do not have lower interest in pursuing Biological sciences compared to the other profiles, but they do have lower interest in pursuing Technological, physical, and computer sciences and in Mathematics and natural sciences compared to Profile 3 (the profile with low concerns overall). Profile 1 showed relatively lower concerns in Biological sciences compared to the other two STEM fields as well, even though they reported more concerns overall than Profile 3; and this might also explain — just like with Profile 2-why they did not have relatively lower interest in Biological sciences, but did have relatively lower interest in Technological, physical, and computer sciences and in Mathematics and natural sciences compared to Profile 3. Finally, Profile 3 showed relatively low concerns overall, and particularly low concerns for Mathematics and natural sciences. Interestingly, these relatively low concerns compared to the other two profiles only translated in relatively more interest in the Mathematics and natural sciences and the Technological, physical, and computer sciences compared to the other two profiles, and not to more interest in Biological sciences.

\section{Discussion}

Although women's representation differs vastly across STEM fields, most research to date looks at STEM overall or focuses on one STEM field specifically (Cheryan et al., 2017). The present study advances our understanding of this variability between STEM fields by examining how high school girls in the process of making important higher education decisions compared STEM fields to each other. We focused on anticipated belonging across STEM fields because belonging has been shown to be a pivotal factor for understanding interest in pursuing a field and for women's underrepresentation in STEM in general (Master et al., 2016). We expected and found that anticipated belonging differed across STEM fields, but also that there were different groups that showed different belonging patterns. Examining these anticipated belonging patterns helped understand variability in interest to pursue different STEM fields. By not only looking within but also across fields, we saw how comparisons between fields easily pulled high school girls towards the Biological 
sciences-a field in which women are much less underrepresented compared to other STEM fields. Thus, to understand variability in women's underrepresentation across STEM fields it is key to look at belonging comparisons between STEM fields.

\subsection{Variability in belonging patterns across STEM fields and how this helps to understand variability in STEM interest}

First of all, we found that the largest group of high school girls anticipated more concerns about belonging in a STEM field the more women are underrepresented in that STEM field. That is, they anticipated the highest belonging concerns in Technological, physical, and computer sciences, followed by Mathematics and natural sciences, and followed by lowest concerns in Biological sciences. This is in line with our argumentation that STEM fields in which women are more strongly underrepresented threaten belonging more because these fields are more strongly associated with masculine characteristics and negative gender stereotypes (Cheryan et al., 2017). This finding in itself already suggests the importance of differentiating between STEM fields, and supports the idea that key information about differences between STEM fields is lost when they are collapsed and STEM is examined as a monolithic category. This is also particularly meaningful given that only very few papers have compared STEM fields to one another, and these papers compared them on other dimensions than belonging (e.g., self-efficacy [Deemer et al., 2014] or gender bias [Milkman et al., 2015]; see also Cheryan et al., 2017).

Importantly, the person-focused approach in this paper enabled us to examine whether the belonging pattern across STEM fields is the same for all girls, or whether different groups of girls make different comparisons across STEM fields. The latter turned out to be the case. In addition to the biggest group, the latent profile analysis showed two additional (equally-sized) profiles of belonging patterns across STEM fields. A second profile had high concerns about belonging overall, but relatively lower concerns in Biological sciences (the field with the highest representation of women) compared to the other two STEM fields. A third profile had low belonging concerns overall, but relatively the highest in Technological, physical, and computer sciences (the field with the strongest underrepresentation of women) and the lowest in Mathematics and natural sciences. The person-focused analysis is an underutilized approach in vocational research and provided information that would have been lost in a variable-focused analysis (Hofmans et al., 2020). A variable-focused analysis would have only shown that girls anticipate, on average, higher belonging concerns in the STEM fields where women are more strongly underrepresented. However, the person-focused analysis showed that this is not the case for everyone, and that different groups make different comparisons between STEM fields. Finding these different belonging patterns is important because the present study showed that for interest in pursuing specific STEM fields it is often not just about the level of anticipated belonging within that STEM field, but just as much about the level of anticipated belonging in comparison to another STEM field. Below, we first discuss these comparative findings within the profiles, and then 
between the profiles. Together, the within and between profile findings show the importance of this comparative lens.

Within profiles, for the largest profile (in which girls had more belonging concerns the more women are underrepresented in a STEM field, and overall an average levels of concerns) we found that girls' belonging comparisons mapped onto their interest in pursuing these fields: they had lower interest in a STEM field the more belonging concerns they had. The second profile had high concerns overall but relatively less in Biological sciences compared to the other two STEM fields. However, the pattern of interest in pursuing the STEM fields of these girls looked similar to the previous profile. So even though they had equal level belonging concerns in the Mathematics and natural sciences and the Technological, physical, and computer sciences, they still showed more interest in pursuing Mathematics and natural sciences. The third profile had low concerns overall, but relatively the highest concerns in Technological, physical, and computer sciences and the lowest in Mathematics and natural sciences. They also showed the lowest interest in Technological, physical, and computer sciences compared to the other two STEM fields. Additionally, unlike the previous two profiles, this profile did not have the highest interest in pursuing Biological sciences as their interest in Biological sciences and Mathematics and natural sciences did not differ significantly. That girls in Profile 3 did not have the highest interest in pursuing Biological sciences might be the case because the other two profiles had the relative lowest belonging concerns in Biological sciences, while this profile had the lowest concerns in Mathematics and natural sciences (compared to the other STEM fields).

Between profiles, the differences were primarily found for interest in pursuing Technological, physical, and computer sciences. The profile with the lowest belonging concerns overall (Profile 3) had the highest interest in Technological, physical, and computer sciences compared to the other two profiles. Thus, even though Profile 3 had within profile the highest belonging concerns in Technological, physical, and computer sciences, they still showed more interest in this field than the other two profiles potentially because their overall belonging concerns were lower. Profile 3 also had the highest interest in Mathematics and natural sciences compared to the other two profiles, but the differences there were relatively small. Importantly, there was no difference between profiles in interest in pursuing Biological sciences. There were big differences between the three profiles in their anticipated belonging concerns in this STEM field and, based on this, one could for example have expected that Profile 3 (with the lowest belonging concerns) would be more interested in pursuing Biological sciences than the other two profiles (as was found for the other two STEM fields). However, this lack of difference can be understood by looking at the comparisons with the other STEM fields within each profile. Although girls in Profiles 1 and 2 had higher belonging concerns in Biological sciences compared to Profile 3, they still had comparatively lower concerns in Biological sciences compared to the other two STEM fields (Technological, physical, and computer sciences and Mathematics and natural sciences). This comparative difference could explain why girls in these two profiles were still equally interested in Biological sciences as girls in Profile 3, despite having more concerns in that field compared to Profile 3. Thus, these relatively lower concerns in the Biological sciences compared to the 
other STEM fields in Profiles 1 and 2 seemed to pull girls in these profiles towards Biological sciences. The comparatively low belonging concerns in Biological sciences in Profile 1 and 2 pulling them towards Biological sciences might also explain why girls in Profile 1 and 2 did have lower interest in Technological, physical, and computer sciences and in Mathematics and natural sciences compared to Profile 3. Finally, it is interesting that for both Technological, physical, and computer sciences and Mathematics and natural sciences it was only the profile with the lowest belonging concerns (Profile 3) that had more interest in these fields; although Profile 1 had lower concerns than Profile 2 in these two STEM fields, there was no difference in interest in pursuing these fields between Profile 1 and 2. Thus, only having really low belonging concerns in these two STEM fields in which women are most strongly underrepresented (Technological, physical, and computer sciences and Mathematics and natural sciences) seemed to make a difference for interest in pursuing these fields. Having somewhat higher concerns in these two STEM fields together with within-profile comparatively lower concerns in Biological sciences (Profiles 1 and 2) pulled girls towards the Biological sciences.

\subsection{The role of comparative processes in educational aspirations}

As discussed in the next section, different samples and educational contexts might show somewhat different profiles than the ones reported in this paper. However, a key take-away from the present findings is the importance of comparative processes in educational aspirations. The above reported findings indicate that to really understand women's underrepresentation in STEM it is key to not just look at how anticipated belonging within a field affects high school girls' interest in pursuing that field. Instead, high school girls compare different STEM fields to each other in terms of anticipated belonging, and thus taking these comparisons into account is key to understand their interest in pursuing these different STEM fields. For example, it appears that not only anticipating low belonging in Technological, physical, and computer sciences is related to less interest in pursuing that STEM field, but also that anticipating relatively more belonging in Biological sciences compared to Technological, physical, and computer sciences draws girls more to the Biological sciences. Thus, high school girls do not just feel pushed out of the more underrepresented fields (such as Technological, physical, and computer sciences) because of lower anticipated belonging there, but anticipating relatively more belonging in less underrepresented fields (such as Biological sciences) pulls them more towards those fields. As such, examining these belonging comparisons across STEM fields helps understanding of variability in interest between STEM fields, and why women are more underrepresented in some STEM fields than others.

The present study also makes a key contribution to the literature on dimensional comparison theory (Möller \& Marsh, 2013). Until now, the literature on dimensional comparisons primarily looked at how individuals use information about their achievement across different domains or school subjects. In a recent extension of this theory (the generalized I/E model; Möller et al., 2015, 2016), Möller and colleagues have proposed that individuals might use any psychologically relevant construct for 
dimensional comparison. Initial support for this was found with teacher support in school subjects (Dietrich et al., 2015), and more recently subjective task values have also been argued to be relevant in dimensional comparisons (Wigfield et al., 2020). The present study focused on anticipated belonging, because this is a particularly relevant construct to understand women's underrepresentation in STEM in general, and because a focus on achievement is not enough to understand women's underrepresentation in STEM (Master et al., 2016; Wang et al., 2013). ${ }^{1}$ We showed that these dimensional comparisons indeed seem to occur for belonging in STEM fields. Thus, this supports the theory that dimensional comparisons might occur for any psychologically relevant construct.

\subsection{Limitations and future research directions}

A first limitation of the present study was that the reliability of the higher education interest measure of the Mathematics and natural sciences category was low. This is potentially the case because that STEM field category contained a more diverse combination of majors compared to the other two STEM field categories. The reason that the items were combined in the present study was to make it comparable to the belonging concerns measure, which asked items about the entire category of Mathematics and natural sciences (instead of per major). Future research could address this by looking at the majors in this category separately instead of together. This could then also test whether the majors in this category indeed fall into the same categories of STEM fields for belonging concerns and interests. However, this is also less of a concern for the current paper, which was more focused on the principle of belonging comparisons than on any specific differences between the specific major choices in a specific time and place.

An open question remains what factors influence the found differences between the belonging patterns across profiles - that is, not just the level of belonging concerns in STEM overall, but the qualitative differences in the patterns. It was beyond the scope of the present paper to examine this, but previous research has provided insight into influences on the level of (anticipated) belonging in a STEM field more generally. These influences could also affect the belonging comparisons across fields. For example, if a girl had many positive experiences at school regarding mathematics then this likely increases her anticipated belonging in this STEM field (Cheryan et al., 2017). An increased anticipation of belonging in this STEM field (Mathematics and natural sciences) could then also change the comparisons with the other STEM fields, such as anticipating an equal level of belonging as in Biological sciences. Future research could examine the consequences of positive experiences

\footnotetext{
1 The present study also contained a measure of anticipated achievement concerns across the three STEM fields. Although it is not possible to control for achievement concerns in the Latent Profile Analysis, the supplemental material does report the estimated marginal means for interest in pursuing the three STEM fields by belonging profile-group, controlled for achievement concerns in each STEM field. The means and standard errors are almost identical with achievement concerns added as a control. Thus, the pattern of interest in pursuing the three STEM fields across the three profile-groups of anticipated belonging cannot be explained by anticipated achievement concerns in the STEM fields.
} 
in one STEM field - and also other factors that have been shown to increase belonging-for the belonging comparisons girls make across STEM fields (e.g., STEM exposure via parents and siblings, exposure to role models, and reducing the presence of stereotypical cues; Cheryan et al., 2009; Van der Vleuten et al., 2018, 2020). Such research would also provide more causal evidence as to the consequences of belonging comparisons for their interest in pursuing different STEM fields. This would address the limitation of the present study that the results were of correlational nature (although previous studies have indeed shown the causal influence of belonging on interest in pursuing STEM fields; Cheryan et al., 2017).

Another question is to what extent these findings are generalizable to other populations. The present study focused on high school girls in STEM-focused tracks. Because these girls are already in a STEM-focused track, they tend to be oriented towards higher education in STEM and biomedical fields. The question is whether we would find the same anticipated belonging patterns across STEM fields with a sample of girls who are in a high school track not specifically focused on STEM, or a sample of high school girls in a Humanities or Social sciences-focused school track. It could for example be the case that differentiating between and comparing STEM fields is not very relevant for high school girls who are less oriented towards STEM in the first place; they might lump all STEM fields together more compared to the girls in the present sample, and perhaps make belonging comparisons between STEM and Humanities. On the other hand, we might expect that high school girls in Humanities and Social sciences-focused tracks use such comparative processes for different Humanities fields ("do I anticipate more belonging in economics, philosophy, or history?"). Indeed, people may be most likely to use such comparative processes for fields that are more self-relevant. This would be an interesting direction for future research.

Finally, the present research was conducted in a Western-European context. This educational context might have had an influence on the relevance of comparative processes. As outlined in the introduction, the participating girls in the present study were one year removed from having to make decisions regarding higher education, and in this context this is a crucial decision-making stage. Once made, their resulting higher education choice is relatively fixed, especially compared to other educational systems such as the US. The comparative process of belonging we found in the Western-European context might be particularly relevant for students when they are in such crucial decision-making stages. It would be interesting for future research to examine whether these comparative processes indeed occur more in crucial decision-making stages, and to examine the influence of educational systems on whether or not students use comparative processes and what types of comparisons are made in that context.

\subsection{Conclusion}

The present paper showed that high school girls in the process of making important higher education choices compared STEM fields to each other in terms of the belonging they anticipated in each field. Although most girls anticipated more 
concerns about belonging the more girls are underrepresented in the STEM field, there were also girls who anticipated only relatively lower concerns in Biological sciences compared to the other STEM fields, and girls who anticipated relatively low concerns overall and especially in Mathematics and natural sciences. Examining these different belonging patterns across STEM fields provided novel insight into variability in STEM interest by suggesting that for interest in pursuing specific STEM fields it is not just about the level of anticipated belonging within that STEM field, but just as much about the level of anticipated belonging in comparison to another STEM field. We hope that the current paper helps to stimulate a stronger focus on these comparative processes in research on educational aspirations.

Supplementary Information The online version contains supplementary material available at https://doi. org/10.1007/s11218-021-09663-6.

Acknowledgements We thank Margriet Van Bael for her useful comments and advice in this project.

Funding This work was supported by an Odysseus grant to Colette Van Laar (Grant Number G.O.E66.14 N) and a fellowship grant to Jenny Veldman (Grant Number 11A2418N), both from the Research Foundation of Flanders.

Data availability https://osf.io/sdwkg/?view_only=c23ea77e74164a6a9d0c3ff93e7dca5c.

\section{Declarations}

Conflict of interest No conflicts of interest.

\section{References}

Baumeister, R. F., \& Leary, M. R. (1995). The need to belong: Desire for interpersonal attachments as a fundamental human motivation. Psychological Bulletin, 117, 497-529. https://doi.org/10.1037/ 0033-2909.117.3.497

Belanger, A. L., Joshi, M. P., Fuesting, M. A., Weisgram, E. S., Claypool, H. M., \& Diekman, A. B. (2020). Putting belonging in context: Communal affordances signal belonging in STEM. Personality and Social Psychology Bulletin, 8, 1186-1204. https://doi.org/10.1177/0146167219897181

Bian, L., Leslie, S. J., \& Cimpian, A. (2017). Gender stereotypes about intellectual ability emerge early and influence children's interests. Science, 355, 389-391. https://doi.org/10.1126/science.aah6524

Breda, T., \& Napp, C. (2019). Girls' comparative advantage in reading can largely explain the gender gap in math-related fields. Proceedings of the National Academy of Sciences. https://doi.org/10.1073/ pnas. 1905779116

Casad, B. J., Petzel, Z. W., \& Ingalls, E. A. (2019). A model of threatening academic environments predicts women STEM majors' self-esteem and engagement in STEM. Sex Roles, 80, 469-488. https:// doi.org/10.1007/s11199-018-0942-4

Ceci, S. J., Ginther, D. K., Kahn, S., \& Williams, W. M. (2014). Women in academic science: A changing landscape. Psychological Science in the Public Interest, 15, 75-141. https://doi.org/10.1177/15291 00614541236

Ceci, S. J., Williams, W. M., \& Barnett, S. M. (2009). Women's underrepresentation in science: Sociocultural and biological considerations. Psychological Bulletin, 135, 218-261. https://doi.org/10.1037/ $\mathrm{a} 0014412$

Cejka, M. A., \& Eagly, A. H. (1999). Gender-stereotypic images of occupations correspond to the sex segregation of employment. Personality and Social Psychology Bulletin, 25, 413-423. https://doi. org/10.1177/0146167299025004002 
Cheryan, S., Plaut, V. C., Davies, P. G., \& Steele, C. M. (2009). Ambient belonging: How stereotypical cues impact gender participation in computer science. Journal of Personality and Social Psychology, 97, 1045-1060. https://doi.org/10.1037/a0016239

Cheryan, S., Ziegler, S. A., Montoya, A. K., \& Jiang, L. (2017). Why are some STEM fields more gender balanced than others? Psychological Bulletin, 143, 1-35. https://doi.org/10.1037/bul0000052

Deemer, E. D., Thoman, D. B., Chase, J. P., \& Smith, J. L. (2014). Feeling the threat: Stereotype threat as a contextual barrier to women's science career choice intentions. Journal of Career Development, 41, 141-158. https://doi.org/10.1177/0894845313483003

Dietrich, J., Dicke, A. L., Kracke, B., \& Noack, P. (2015). Teacher support and its influence on students' intrinsic value and effort: Dimensional comparison effects across subjects. Learning and Instruction, 39, 45-54. https://doi.org/10.1016/j.learninstruc.2015.05.007

Ellemers, N. (2018). Gender stereotypes. Annual Review of Psychology, 69, 275-298. https://doi.org/10. 1146/annurev-psych-122216-011719.

Fiske, S. (2018). Social beings: Core motives in social psychology. Wiley \& Sons.

Gabriel, S. (2021). Reflections on the 25th anniversary of Baumeister \& Leary's seminal paper on the need to belong. Self and Identity, 20, 1-5. https://doi.org/10.1080/15298868.2020.1850518

Gaucher, D., Friesen, J., \& Kay, A. C. (2011). Evidence that gendered wording in job advertisements exists and sustains gender inequality. Journal of Personality and Social Psychology, 101, 109-128. https://doi.org/10.1037/a0022530

Geiser, C. (2013). Data analysis with Mplus. Methodology in the social sciences. Guilford Press.

Good, C., Rattan, A., \& Dweck, C. S. (2012). Why do women opt out? Sense of belonging and women's representation in mathematics. Journal of Personality and Social Psychology, 4, 700-717. https:// doi.org/10.1037/a0026659

Guo, J., Parker, P. D., Marsh, H. W., \& Morin, A. J. S. (2015). Achievement, motivation, and educational choices: A longitudinal study of expectancy and value using a multiplicative perspective. Developmental Psychology, 8, 1163-1176. https://doi.org/10.1037/a0039440

Hickendorff, M., Edelsbrunnerb, P. A., McMullenc, J., Schneiderd, M., \& Kelly, T. (2018). Informative tools for characterizing individual differences in learning: Latent class, latent profile, and latent transition analysis. Learning and Individual Differences, 66, 4-15. https://doi.org/10.1016/j.lindif.2018. 06.001

Hofmans, J., Wille, B., \& Schreurs, B. (2020). Person-centered methods in vocational research. Journal of Vocational Behavior, 118, 103398. https://doi.org/10.1016/j.jvb.2020.103398

Jansen, M., Schroeders, U., Lüdtke, O., \& Marsh, H. W. (2015). Contrast and assimilation effects of dimensional comparisons in five subjects: An extension of the I/E Model. Journal of Educational Psychology, 107, 1086-1101. https://doi.org/10.1037/edu0000021

KU Leuven. (2014). Diversity Policy Plan 2014-2017. Retrieved from https://www.kuleuven.be/diver siteit/pdf/6566_BRO_BELEIDSPLAN_DIV_UK.pdf.

Law, H. (2018). Gender and mathematics: Pathways to mathematically intensive fields of study in Australia. Advances in Life Course Research, 37, 42-56. https://doi.org/10.1016/j.alcr.2018.07.002

Leary, M. R., \& Cox, C. (2008). Belongingness motivation. In J. Shah \& W. Gardner (Eds.), Handbook of motivation science (pp. 27-40). The Guilford Press.

Leslie, S. J., Cimpian, A., Meyer, M., \& Freeland, E. (2015). Expectations of brilliance underlie gender distributions across academic disciplines. Science, 347, 262-265. https://doi.org/10.1126/science. 1261375

Major, B., \& Schmader, T. (2017). Stigma, social identity threat, and health. In B. Major, J. F. Dovidio, \& B. G. Link (Eds.), Oxford library of psychology. The Oxford handbook of stigma, discrimination, and health (pp. 85-103). Oxford University Press.

Marsh, H. W. (1986). Verbal and math self-concepts: An internal/external frame of reference model. American Educational Research Journal, 23, 129-149. https://doi.org/10.2307/1163048

Marsh, H. W., Lüdtke, O., Trautwein, U., \& Morin, A. J. S. (2009). Classical latent profile analysis of academic self-concept dimensions: Synergy of person- and variable-centered approaches to theoretical models of self-concept. Structural Equation Modeling: A Multidisciplinary Journal, 16, 191225. https://doi.org/10.1080/10705510902751010

Marsh, H., Seaton, M., Dicke, T., Parker, P., \& Horwood, M. (2019). The centrality of academic selfconcept to motivation and learning. In K. Renninger \& S. Hidi (Eds.), The Cambridge handbook of motivation and learning (pp. 36-62). Cambridge University Press. 
Master, A., Cheryan, S., \& Meltzoff, A. N. (2016). Computing whether she belongs: Stereotypes undermine girls' interest and sense of belonging in computer science. Journal of Educational Psychology, 108, 424-437. https://doi.org/10.1037/edu0000061

Milkman, K. L., Akinola, M., \& Chugh, D. (2015). What happens before? A field experiment exploring how pay and representation differentially shape bias on the pathway into organizations. Journal of Applied Psychology, 100, 1678-1712. https://doi.org/10.1037/ap10000022

Möller, J., Helm, F., Müller-Kalthoff, H., Nagy, N., \& Marsh, H. W. (2015). Dimensional comparisons and their consequences for self-concept, motivation, and emotion. International Encyclopedia of the Social \& Behavioral Sciences, 26, 430-436. https://doi.org/10.1016/B978-0-08-097086-8.26092-3

Möller, J., \& Köller, O. (2001). Dimensional comparisons: An experimental approach to the internal/ external frame of reference model. Journal of Educational Psychology, 93, 826-835. https://doi.org/ 10.1037/0022-0663.93.4.826

Möller, J., \& Marsh, H. W. (2013). Dimensional comparison theory. Psychological Review, 120, 544560. https://doi.org/10.1037/a0032459

Möller, J., Müller-Kalthoff, H., Helm, F., Nagy, N., \& Marsh, H. W. (2016). The generalized internal/ external frame of reference model: An extension to dimensional comparison theory. Frontline Learning Research, 4, 1-11. https://doi.org/10.14786/flr.v4i2.169

Möller, J., Pohlmann, B., Köller, O., \& Marsh, H. W. (2009). A meta-analytic path analysis of the internal/external frame of reference model of academic achievement and academic self-concept. Review of Educational Research, 79, 1129-1167. https://doi.org/10.3102/0034654309337522

Murphy, M. C., Steele, C. M., \& Gross, J. J. (2007). Signaling threat: How situational cues affect women in math, science, and engineering settings. Psychological Science, 18, 879-885. https://doi.org/10. 1111/j.1467-9280.2007.01995.x

Muthén, L. K., \& Muthén, B. O. (1998). Mplus user's guide. Los Angeles, CA: Muthén \& Muthén.

National Science Foundation. (2014). Integrated Postsecondary Education Data System, 2013, Completions Survey. National Center for Science and Engineering Statistics: Integrated Science and Engineering Resources Data System (WebCASPAR). Retrieved from https://webcaspar.nsf.gov.

Rost, J. (2006). Latent-Class-Analyse [Latent class analysis]. In F. Petermann \& M. Eid (Eds.), Handbuch der psychologischen Diagnostik [Handbook of psychological assessment] (pp. 275-287). Hogrefe.

Ryan, R. M., \& Deci, E. L. (2000). Self-determination theory and the facilitation of intrinsic motivation, social development, and well-being. American Psychologist, 55, 68. https://doi.org/10.1037/0003066X.55.1.68

Smith, J. L., Deemer, E. D., Thoman, D. B., \& Zazworsky, L. (2014). Motivation under the microscope: Understanding undergraduate science students' multiple motivations for research. Motivation and Emotion, 38, 496-512. https://doi.org/10.1007/s11031-013-9388-8

Smith, J. L., Lewis, K. L., Hawthorne, L., \& Hodges, S. D. (2013). When trying hard isn't natural: Women's belonging with and motivation for male-dominated STEM fields as a function of effort expenditure concerns. Personality and Social Psychology Bulletin, 39, 131-143. https://doi.org/10.1177/ 0146167212468332

STEM monitor (2020). STEM monitor juni 2020. Retrieved from https://publicaties.vlaanderen.be/viewfile/39179.

Stoet, G., \& Geary, D. C. (2018). The gender-equality paradox in science, technology, engineering, and mathematics education. Psychological Science, 29, 581-593. https://doi.org/10.1177/0956797617 741719

Storage, D., Charlesworth, T. E., Banaji, M. R., \& Cimpian, A. (2020). Adults and children implicitly associate brilliance with men more than women. Journal of Experimental Social Psychology, 90, 104020. https://doi.org/10.1016/j.jesp.2020.104020

Thoman, D. B., Arizaga, J. A., Smith, J. L., Story, T. S., \& Soncuya, G. (2014). The grass is greener in non-science, technology, engineering, and math classes: Examining the role of competing belonging to undergraduate women's vulnerability to being pulled away from science. Psychology of Women Quarterly, 38, 246-258. https://doi.org/10.1177/0361684313499899

van der Vleuten, M., Jaspers, E., Maas, I., \& van der Lippe, T. (2018). Intergenerational transmission of gender segregation: How parents' occupational field affects gender differences in field of study choices. British Educational Research Journal, 44, 294-318. https://doi.org/10.1002/berj.3329

van der Vleuten, M., Weesie, J., \& Maas, I. (2020). Sibling influence in field of study choices. Research in Social Stratification and Mobility, 68, 100525. https://doi.org/10.1016/j.rssm.2020.100525 
Van Laar, C., Meeussen, L., Veldman, J., Van Grootel, S., Sterk, N., \& Jacobs, C. (2019). Coping with stigma in the workplace: Understanding the role of threat regulation, supportive factors, and potential hidden costs. Frontiers in Psychology, 10, 1879. https://doi.org/10.3389/fpsyg.2019.01879.

Vignoles, V. (2011). Identity motives. In S. Schwartz, K. Luyckx, \& V. Vignoles (Eds.), Handbook of identity theory and research (pp. 403-432). Springer.

Wang, M. T., \& Degol, J. (2013). Motivational pathways to STEM career choices: Using expectancyvalue perspective to understand individual and gender differences in STEM fields. Developmental Review, 33, 304-340. https://doi.org/10.1016/j.dr.2013.08.001

Wang, M. T., Eccles, J. S., \& Kenny, S. (2013). Not lack of ability but more choice: Individual and gender differences in choice of careers in science, technology, engineering, and mathematics. Psychological Science, 24, 770-775. https://doi.org/10.1177/0956797612458937

Wigfield, A., Eccles, J. S., \& Möller, J. (2020). How dimensional comparisons help to understand linkages between expectancies, values, performance, and choice. Educational Psychology Review, 32, 657-680. https://doi.org/10.1007/s10648-020-09524-2

Publisher's Note Springer Nature remains neutral with regard to jurisdictional claims in published maps and institutional affiliations.

Jenny Veldman is a Postdoctoral Research Associate at the Center for Social and Cultural Psychology (University of Leuven, Belgium) and a Research Fellow at the Flanders Science Foundation. She is a social psychological researcher focusing on understanding the underrepresentation of certain social groups in work and education fields (e.g., low SES students at university and women in STEM, the police force, and the military). Her primary research examines how members of such underrepresented groups cope with the challenges they face (e.g., to obtain a sense of belonging) rather than passively undergo these challenges, and how this maintains or challenges organizational inequalities.

Colette Van Laar is Full Professor at the Center for Social \& Cultural Psychology, University of Leuven. Her research examines social psychological factors and processes that transfer negative group stereotypes and prejudice into lower outcomes in education and work. She examines well-being, motivation and performance in women in a number of fields, including girls with regard to math, young Muslim women in education and the labor market, and women pursuing upward mobility and leadership positions in the police force, telecom, banking and other organizations in which they have traditionally been underrepresented.

Dustin B. Thoman is a faculty member in the Department of Psychology at San Diego State University. His work focuses on the development of student interest, and the influence of stereotypes and social identities in shaping the development of students' educational and career interests. Through consulting and program development, he also works to improve educational programs, particularly those designed to broaden participation and promote diversity in science and math education, through theoretically and empirically-grounded approaches.

Carolien Van Soom is Associate Professor at the University of Leuven, head of the Tutorial Services and Educational Development \& Innovation unit at the Faculty of Science, and team leader of the LESEC Research Team on Study Career guidance of STEM students. Her research interest focuses on cognitive and non-cognitive predictors of academic achievement and drop-out, changes in motivation and academic self-concept during the first year of higher STEM education, and on gender and study choice. She develops and coordinates outreach events to raise interest of female adolescents in exact sciences. 


\section{Authors and Affiliations}

\section{Jenny Veldman ${ }^{1,2}$ (D) Colette $\operatorname{Van}_{\operatorname{Laar}^{1}}$ C Dustin B. Thoman ${ }^{3}$. Carolien Van Soom ${ }^{4,5}$ (D)}

1 Center for Social and Cultural Psychology, Department of Psychology, University of Leuven, Leuven, Belgium

2 Research Foundation - Flanders, Brussels, Belgium

3 Department of Psychology and Center for Research in Mathematics and Science Education, San Diego State University, San Diego, USA

4 Leuven Engineering and Science Education Center (LESEC), Leuven, Belgium

5 Faculty of Science, University of Leuven, Leuven, Belgium 